\title{
Biological effects of bone marrow mesenchymal stem cells on hepatitis $B$ virus in vitro
}

\author{
WEI-PING ZHENG $^{1 *}$, BO-YA ZHANG ${ }^{2 *}$, ZHONG-YANG SHEN $^{1}$, MING-LI YIN ${ }^{2}$, YI CAO $^{2}$ and HONG-LI SONG ${ }^{1,3}$ \\ ${ }^{1}$ Department of Organ Transplantation, Tianjin First Central Hospital, Tianjin 300192; \\ ${ }^{2}$ Tianjin First Central Hospital Clinic Institute, Tianjin Medical University, Tianjin 300070; \\ ${ }^{3}$ Tianjin Key Laboratory of Organ Transplantation, Tianjin 300192, P.R. China
}

Received November 26, 2015; Accepted December 9, 2016

DOI: $10.3892 / \mathrm{mmr} .2017 .6330$

\begin{abstract}
The aim of the present study was to explore the effects of co-culturing bone marrow-derived mesenchymal stem cells (BM-MSCs) cultured with hepatitis B virus (HBV)-infected lymphocytes in vitro. BM-MSCs and lymphocytes from Brown Norway rats were obtained from the bone marrow and spleen, respectively. Rats were divided into the following five experimental groups: Group 1, splenic lymphocytes (SLCs); group 2, HepG2.2.15 cells; group 3, BM-MSCs + HepG2.2.15 cells; group 4, SLCs + HepG2.2.15 cells; and group 5, SLCs + BM-MSCs + HepG2.2.15 cells. The viability of lymphocytes and HepG2.2.15 cells was assessed using the MTT assay at 24, 48 and $72 \mathrm{~h}$, respectively. Levels of supernatant HBV DNA and intracellular HBV covalently closed circular DNA (cccDNA) were measured using quantitative polymerase chain reaction. Supernatant cytokine levels were measured by enzyme-linked immunosorbent assay (ELISA). T cell subsets were quantified by flow cytometry using fluorescence-labeled antibodies. In addition, the HBV genome sequence was analyzed by direct gene sequencing. Levels of HBV DNA and cccDNA in group 5 were lower when compared with those in group 3 or group 4, with a significant difference observed at $48 \mathrm{~h}$. The secretion of interferon $\gamma$ was negatively correlated with the level of HBV
\end{abstract}

Correspondence to: Professor Hong-Li Song, Department of Organ Transplantation, Tianjin First Central Hospital, 24 Fukang Road, Nankai, Tianjin 300192, P.R. China

E-mail: hlsong26@163.com

*Contributed equally

Abbreviations: BM-MSCs, bone marrow-derived mesenchymal stem cells; SLCs, splenic lymphocytes; HBV, Hepatitis B virus; BN, Brown Norway; UC-MSCs, umbilical cord-derived mesenchymal stem cells; DMEM, Dulbecco's modified Eagle's medium; MTT, methylthiazolyl tetrazolium; EGF, epidermal growth factor; HGF, hepatocyte growth factor

Key words: hepatitis B virus, bone marrow mesenchymal stem cells, lymphocytes, cytokines, gene sequence
DNA, whereas secretion of interleukin (IL)-10 and IL-22 were positively correlated with the level of HBV DNA. Flow cytometry demonstrated that the percentage of $\mathrm{CD}^{+}{ }^{+} \mathrm{CD} 8^{+}$ $\mathrm{T}$ cells was positively correlated with the levels of $\mathrm{HBV}$ DNA, and the $\mathrm{CD}^{+} \mathrm{CD}^{+} / \mathrm{CD}^{+}{ }^{+} \mathrm{CD} 8^{+}$ratio was negatively correlated with the level of HBV DNA. Almost no mutations in the HBV DNA sequence were detected in HepG2.2.15 cells co-cultured with BM-MSCs, SLCs, or in the two types of cells combined. BM-MSCs inhibited the expression of HBV DNA and enhanced the clearance of HBV, which may have been mediated by the regulation of the Tc1/Tc2 cell balance and the mode of cytokine secretion to modulate cytokine expression.

\section{Introduction}

In China, the yearly mortality rate for end-stage liver disease is $>300,000$ patients (1). Of the $>30$ million patients with chronic liver disease in China, $\sim 80 \%$ are infected with the hepatitis B virus (HBV) (2). The most effective treatment for $\mathrm{HBV}$-associated end-stage liver disease is liver transplantation. However, without effective prophylaxis, the risk of HBV re-infection following transplantation may reach $>80 \%(3,4)$. The current treatment protocol of nucleos(t)ide analogues combined with hepatitis B immunoglobulin (HBIG) following liver transplantation, greatly reduces the hepatitis B recurrence rate $(2,5,6)$. However, the high cost remains a heavy burden for patients $(7,8)$, and the long-term use of nucleos(t)ide analogues may lead to HBV resistance $(9,10)$. Application of the HBV vaccine following liver transplantation may potentially lead to the withdrawal of nucleoside analogues and HBIG therapy, however the vaccine is less effective due to the use of immunosuppressants following transplantation $(11,12)$. Therefore, it is important to identify novel methods to prevent hepatitis B recurrence following liver transplantation.

Bone marrow-derived mesenchymal stem cells (BM-MSCs) have demonstrated anti-inflammatory $(13,14)$ and angiogenesis-enhancing effects $(15,16)$ with low immunogenicity $(17,18)$. In addition, BM-MSCs exhibit immunomodulatory capabilities in animal models of rejection following transplantation (19-21), which may represent a promising method for inducing immune tolerance. Transfusions of umbilical cord-derived MSCs for patients with HBV-associated acute-on-chronic liver failure resulted 
in improved liver function and alleviated liver damage (22). However, the biological effects of BM-MSCs on HBV have not yet been reported. In the present study, the effect of BM-MSCs on HBV replication and genome mutation in vitro was investigated, as well as its associated mechanisms. The results of the current study may provide innovative strategies for the prevention of hepatitis $\mathrm{B}$ recurrence following liver transplantation.

\section{Materials and methods}

Animals and cell lines. A total of 12 specific pathogen-free Brown Norway (BN) male rats (age, 4-5 weeks; body weight, 200-220 g) were used for the isolation and identification of BM-MSCs. Inbred male BN rats were kept 2 rats per cage at $24^{\circ} \mathrm{C}$, with $50 \%$ humidity and a $12 \mathrm{~h}$ light and dark cycle, with free access to water and food. An additional 6 specific pathogen-free $\mathrm{BN}$ male rats (age, 4-5 weeks; body weight, 200-220 g) were used for the extraction of splenic lymphocytes (SLCs), and were kept under the same conditions as described above. All animals were purchased from the Chinese Academy of Military Medical Sciences (Beijing, China). The use of animals and the animal experimental procedures employed for the purposes of this study were approved by the Ethics Committee of Tianjin First Central Hospital (Tianjin, China). The human hepatocellular carcinoma cell line HepG2.2.15 was donated by Professor Wei Lai (Hepatology Institute of Peking University Affiliated Hospital, Beijing, China), and contained the complete HBV genome, as well as expressed HBV-associated antigens and secreted whole Dane particles $(23,24)$.

Instruments and reagents. The following instruments and reagents were used: Dulbecco's modified Eagle's medium (DMEM) and DMEM/F12 media (1:1; Hyclone, Logan, UT, USA), G418 (Gibco; Thermo Fisher Scientific, Inc., Waltham, MA, USA), fetal bovine serum (FBS; Biowest, Nuaille, France), transwell plates (Corning, Inc., Corning, NY, USA), MTT reagent (Beijing Dingguo Changsheng Biotechnology, Co., Ltd., Beijing, China), dimethyl sulfoxide (DMSO; Amresco, Solon, OH, USA), lymphocyte separation medium (Beijing Dingguo Changsheng Biotechnology, Co., Ltd.), TRIzol (Invitrogen; Thermo Fisher Scientific, Inc.), antibodies directed against CD29 (cat. no. 102207), CD90 (cat. no. 202503), RT1A (cat. no. 205208), CD45 (cat. no. 202207) and RT1B (cat. no. 205305) for the identification of BM-MSCs (Biolegend, Inc., San Diego, CA, USA), CD34 (cat. no. sc-7324; Santa Cruz Biotechnology, Inc., Dallas, TX, USA), CD3-APC mAb (cat. no. 11-0040-82), CD8a-PE-Cy7 (cat. no. 12-0084-82), and CD4-FITC mAb (cat. no. 11-0040-82; eBiosciences, Inc., San Diego, CA, USA), a cell genomic DNA extraction kit (Beijing Kangwei Century Biotech Co. Ltd., Beijing, China) and enzyme-linked immunosorbent assay (ELISA) kits for measuring IL-10 (cat. no. R1000), IL-22 (cat. no. M2200), and IFN- $\gamma$ (cat. no. RIF00; R\&D Systems, Inc., Minneapolis, MN, USA). Primer sequences used for quantitative polymerase chain reaction (PCR) assay analysis for the detection of HBV covalently closed circular DNA (cccDNA) were as follows: cccDNA, forward, 5'-GTG TGC ACT TCG CTT CAC-3', and reverse, 5'-GGG TCA ATG TCC ATG CC-3' (designed by Shanghai Jikang Biotechnology Company, Co., Ltd., Shanghai, China). The TaqMan probe (5'-FAM-ATG TCC TAC TGT TCA AGC CTC CAA-BHQ-3') was designed by Takara Bio, Inc. (Otsu, Japan). Instruments included the $\mathrm{CO}_{2}$ incubator (Sheldon Manufacturing, Inc., Cornelius, OR, USA), an inverted fluorescence microscope (Olympus Corporation, Tokyo, Japan), the FACSCalibur flow cytometer (BD Biosciences), the ABI PRISM ${ }^{\circledR} 3700$ DNA Analyzer and the fluorescence-based 7500 Fast Real-Time PCR system (Applied Biosystems ${ }^{\mathrm{TM}}$; Thermo Fisher Scientific, Inc.), the automatic fluorescence quantitative flow cytometer (PerkinElmer, Inc., Waltham, MA, USA), and the RT-6000 automatic microplate reader (Omega Bio-Tek, Inc., Norcross, GA, USA). Serum levels of alanine transaminase (ALT) and aspartate aminotransferase (AST) were determined using a 7180 clinical chemistry analyzer (Hitachi High-Technologies Corporation, Tokyo, Japan).

Isolation and identification of BM-MSCs. BM-MSCs were aseptically isolated from the femur and tibia of 12 male $\mathrm{BN}$ rats. Red blood cells were lysed using $0.1 \mathrm{~mol} / 1 \mathrm{NH}_{4} \mathrm{Cl}$, and the remaining cells were washed, resuspended and cultured in DMEM/F12 (1:1) media containing $100 \mathrm{U} / \mathrm{ml}$ penicillin, $100 \mathrm{mg} / \mathrm{ml}$ streptomycin (Gibco; Thermo Fisher Scientific, Inc.), and $15 \%$ FBS. BM-MSCs were cultured in an incubator at $37^{\circ} \mathrm{C}$ and $5 \% \mathrm{CO}_{2}$ with saturating humidity. The medium was refreshed every $48 \mathrm{~h}$. When cells at passage 3 had reached $80 \%$ confluence, cells were trypsinized, washed, centrifuged at $300 \times \mathrm{g}$ for $5 \mathrm{~min}$ at room temperature, and resuspended at $1 \times 10^{7}$ cells $/ \mathrm{ml}$ in phosphate-buffered saline (PBS). BM-MSCs $(100 \mu \mathrm{l})$ were incubated with the following fluorescence-labeled antibodies at $4^{\circ} \mathrm{C}$ for $30 \mathrm{~min}$ in the dark: CD29-PE (1:80), CD34-FITC (1:20), CD45-PE (1:80), CD90-FITC (1:200), RT1A-PE (1:80) and RT1B-FITC (1:200). Cells were then washed with PBS and analyzed by flow cytometry (FACSCalibur; BD Biosciences) to determine the phenotype and purity of BM-MSCs.

Harvesting of rat SLCs. Spleens of 6 rats were extracted following sacrifice by cervical dislocation under aseptic conditions, disassociated by grinding, and then filtered through a $200-\mu$ m nylon mesh. Cell suspensions were transferred to a centrifuge tube containing Percoll lymphocyte separation medium (1.083 g/ml; Beijing Dingguo Changsheng Biotechnology, Co., Ltd., Beijing, China). Following centrifugation at $670 \mathrm{x} g$ for $20 \mathrm{~min}$ at room temperature, the white middle layer was extracted and centrifuged at $330 \mathrm{x} g$ for $8 \mathrm{~min}$ at room temperature, before the supernatant was discarded. After washing with PBS, the lymphocytes were counted and cultured in RPIM 1640 media (Gibco; Thermo Fisher Scientific, Inc.) containing $100 \mathrm{U} / \mathrm{ml}$ penicillin, $100 \mathrm{mg} / \mathrm{ml}$ streptomycin, $1 \mathrm{mmol} / \mathrm{l}$ glutamine, and $10 \% \mathrm{FBS}\left(5 \times 10^{5} \mathrm{cells} / \mathrm{ml}\right)$.

HepG2.2.15 cell culture. HepG2.2.15 cells were cultured in high glucose-DMEM (Hyclone; GE Healthcare Life Sciences), which contained 10\% heat-inactivated FBS, 200 mg/l G418, $6 \mathrm{mmol} / 1$ glutamine, $100 \mathrm{U} / \mathrm{ml}$ penicillin and $100 \mathrm{mg} / \mathrm{l}$ streptomycin, in an incubator at $37^{\circ} \mathrm{C}$ and $5 \% \mathrm{CO}_{2}$ with saturating humidity. The medium was refreshed every $48 \mathrm{~h}$, and healthy cells were selected for downstream experiments.

Co-culture of different cell types. The following experimental groups were studied: Group 1, SLCs; group 2, HepG2.2.15 
cells; group 3, BM-MSCs + HepG2.2.15 cells; group 4, SLCs + HepG2.2.15 cells; and group 5, SLCs + BM-MSCs + HepG2.2.15 cells. HepG2.2.15 cells were plated in the lower chamber of a 6-well transwell dish (pore size, $0.4 \mu \mathrm{m}$; Corning, Incorporated) at $1 \times 10^{5}$ cells/well, and SLCs and BM-MSCs were inoculated in the upper chamber of the transwell plate at $5 \times 10^{5}$ cells/well. Plates were cultured at $37^{\circ} \mathrm{C}$ and $5 \% \mathrm{CO}_{2}$ with saturating humidity in an incubator for 24,48 or $72 \mathrm{~h}$. Each group was plated in triplicate wells for each time point. At each time point, supernatants and cells were collected for further analysis.

MTT cell viability assay. Cell suspensions (200 $\mu \mathrm{l})$ from each experimental group were added to each well of a 96-well plate (SLCs, $2 \times 10^{4}$ cells/well; BM-MSCs, $2 \times 10^{4}$ cells/well; HepG2.2.15 cells, $4 \times 10^{3}$ cells/well), which was incubated at $37^{\circ} \mathrm{C}$ with $5 \% \mathrm{CO}_{2}$. Cells were cultured for 24,48 or $72 \mathrm{~h}$. MTT solution $(15 \mu \mathrm{l}$ at $5 \mathrm{~g} / \mathrm{l})$ was added to each well and incubated for $3 \mathrm{~h}$. The medium was subsequently aspirated and DMSO $(100 \mu \mathrm{l})$ was added to each well before the plates were placed on a shaker for $10 \mathrm{~min}$ to fully dissolve the formazan crystals. The absorbance (A) at $490 \mathrm{~nm}$ was measured using an automated microplate reader, and the cell survival rate was calculated using the following formula: Survival rate $=\left(\mathrm{A}_{\text {test well }}-\mathrm{A}_{\text {blank well }}\right) /\left(\mathrm{A}_{\text {control well }}-\mathrm{A}_{\text {blank well }}\right) \times 100 \%$.

Detection of supernatant $H B V D N A$ and intracellular cccDNA of HepG2.2.15 cells and BM-MSCs. The supernatant HBV DNA levels were measured using a real-time PCR kit according to the manufacturer's instructions (Shanghai Kehua Bioengineering Co., Ltd.), using an ABI 7500 Real-Time PCR system. Genomic DNA was extracted from HepG2.2.15 cells ( $2 \times 10^{6}$ cells) or BM-MSCs $\left(5 \times 10^{6}\right.$ cells) using a UniversalGen DNA kit (CWBio, Co., Ltd., Beijing, China), and $2 \mu \mathrm{g} \mathrm{HBV}$ DNA or cccDNA was subjected to quantitative PCR analysis using an optimized quantitative PCR method described previously (25).

$H B V$ genomic DNA extraction and sequencing analysis. HBV genomic DNA was extracted from the supernatants of co-cultured HepG2.2.15 cells using a Viral DNA Isolation kit (DAAN Gene, Co., Ltd., of Sun Yat-sen University, Guangzhou, China) according to the manufacturer's instructions. Briefly, cell supernatants were added to virus lysis buffer, and lysates were loaded onto a spin column. After viral DNA was bound to the membrane, each column was washed and the viral DNA was eluted.

PCR was performed using HBV genomic DNA as a template to amplify the $\mathrm{P}, \mathrm{S}, \mathrm{X}$ and $\mathrm{C}$ regions using the primer sequences listed in Table I. The PCR conditions were as follows: Initial denaturation at $94^{\circ} \mathrm{C}$ for $2 \mathrm{~min}$, followed by 35 cycles of $94^{\circ} \mathrm{C}$ for $30 \mathrm{sec}, 55^{\circ} \mathrm{C}$ for $30 \mathrm{sec}, 72^{\circ} \mathrm{C}$ for $1 \mathrm{~min}$ and a final extension at $72^{\circ} \mathrm{C}$ for $10 \mathrm{~min}$. PCR products were resolved by $2 \%$ agarose gel electrophoresis, and the bands were visualized under ultraviolet light following ethidium bromide staining. The DNA was recovered from the agarose gel using a MiniBEST Agarose Gel DNA Extraction kit (Takara Bio, Inc.) according to the manufacturer's protocol, and the amplified DNA was subjected to sequencing analysis by Sangon Biotech (Shanghai, China).
Table I. Sequences of the primers used for polymerase chain reaction in the present study.

\begin{tabular}{llc}
$\begin{array}{l}\text { Primer } \\
\text { name }\end{array}$ & \multicolumn{1}{c}{ Sequence (5'-3') } & $\begin{array}{c}\text { Length } \\
(\mathrm{bp})\end{array}$ \\
\hline HBV-F1 & GGGTCACCATATTCTTGGGAAC & 22 \\
HBV-R1 & ATTGAGAGAAGTCCACCACGAGT & 23 \\
HBV-F2 & TAGGACCCCTGCTCGTGTTACAG & 18 \\
HBV-R2 & GAACCACTGAACAAATGGCACTAG & 24 \\
HBV-F3 & GAACCTCTATGTTTCCCTCT & 20 \\
HBV-R3 & TGCGTCAGCAAACACTT & 17 \\
HBV-F4 & CCTATTGATTGGAAAGTATG & 20 \\
HBV-R4 & ATGAGAAGGCACAGACG & 17 \\
HBV-F5 & CCGATCCATACTGCGGAACTCC & 22 \\
HBV-R5 & GCTTGGAGGCTTGAACAGTAGGACA & 25 \\
HBV-F6 & TACTAGGAGGCTGTAGGCATAA & 22 \\
HBV-R6 & GTGTTGATAAGATAGGGGCATTT & 23 \\
HBV-F7 & GGTGTCTTTGGAGTGTGGA & 20 \\
HBV-R7 & TTGTTCCCAAGAATATGGTGA & 21 \\
HBV-F8 & AGAACTCCCTCGCCTCG & 17 \\
HBV-R8 & TTGAAGTCCCAATCTGGATT & 20 \\
\hline
\end{tabular}

HBV, hepatitis B virus; F, forward; R, reverse.

Detection of lymphocyte surface markers CD4 and CD8 in the $\mathrm{CD}^{+}$cell by flow cytometry. SLCs were harvested and centrifuged at $300 \times \mathrm{g}$ for $5 \mathrm{~min}$ at $4^{\circ} \mathrm{C}$ following culture for 24,48 or $72 \mathrm{~h}$. Then SLCs $\left(1 \times 10^{6}\right.$ cells $)$ were resuspended in $100 \mu \mathrm{l}$ PBS for detection, and the fluorescence-labeled antibodies anti-CD3-APC (1:80), anti-CD4-FITC (1:200), and anti-CD8a-PE-Cy7 (1:160) were added for incubation at $4{ }^{\circ} \mathrm{C}$ for $30 \mathrm{~min}$ in the dark, to detect the expression intensity of each cell surface marker by flow cytometry.

Detection of supernatant cytokines. Concentrations of IFN- $\gamma$, IL-10, and IL-22 in the cell supernatants were determined using an ELISA kit (R\&D Systems, Inc.) according to the manufacturer's protocol. The absorbance at $450 \mathrm{~nm}$ was measured using an automated microplate reader.

Statistical analysis. SPSS 17.0 (SPSS, Inc., Chicago, IL, USA) was used for statistical analysis. Normally distributed data were presented as the mean \pm standard deviation. Additional data sets were compared by analysis of variance, and Dunnett's method was used when the variance was not homogenous. Linear correlation analysis was used to test the interdependence of the variables. $\mathrm{P}<0.05$ was considered to indicate a statistically significant difference. GraphPad Prism 5.0 software (GraphPad Software, Inc., La Jolla, CA, USA) was used to plot data for presentation.

\section{Results}

Morphology and phenotypic analysis of HepG2.2.15 cells and BM-MSCs. HepG2.2.15 cells were confirmed to be plastic-adherent cells with a spindle-shaped morphology 


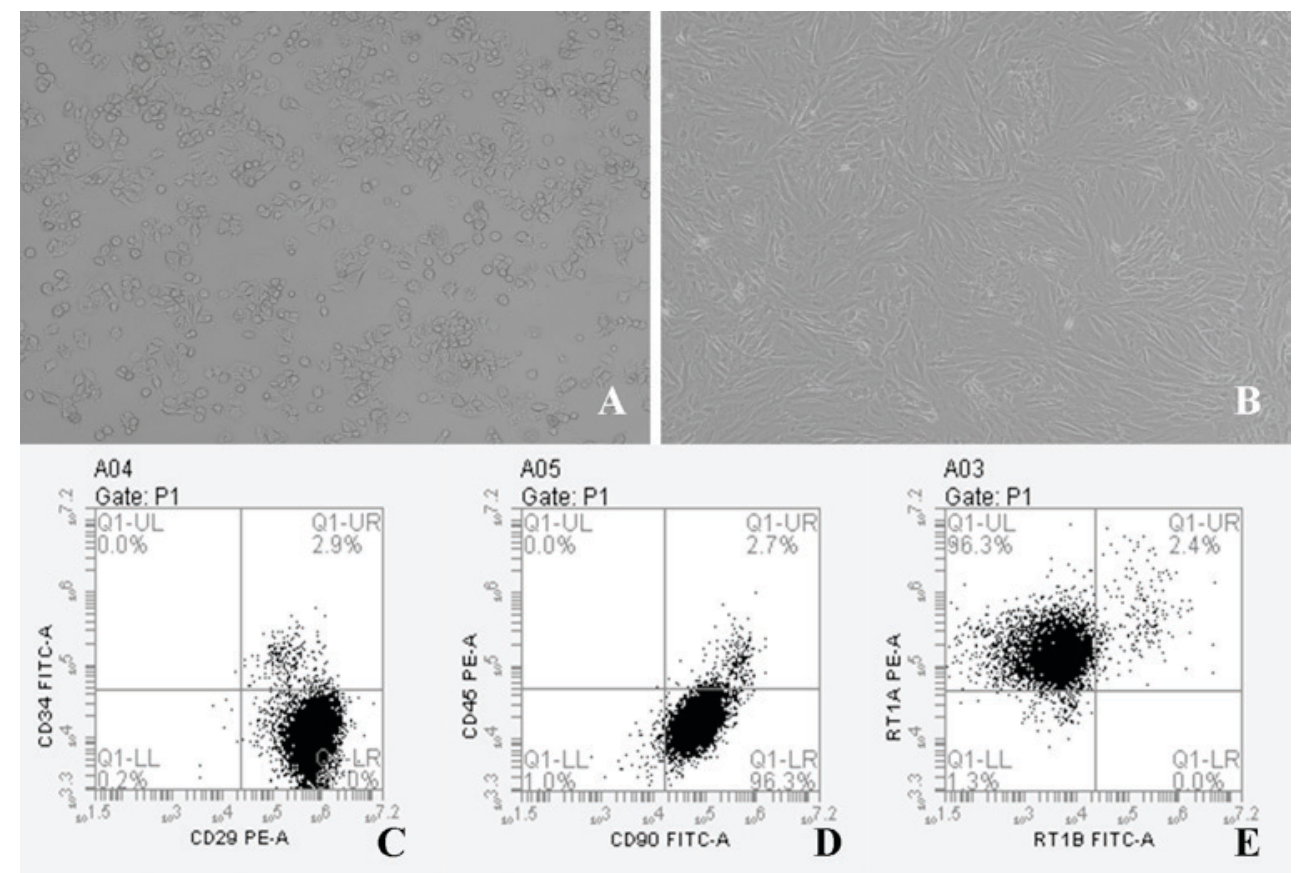

Figure 1. Morphological and flow cytometry analysis of BM-MSCs derived from Brown Norway rats. Microscope images of (A) HepG2.2.15 cells and (B) BM-MSCs at passage 3 (magnification, x100). Flow cytometry analysis of the expression of (C) CD29 and CD34, (D) CD45 and CD90, and (E) RT1A and RT1B. BM-MSCs, bone marrow-derived mesenchymal stem cells; FITC, fluorescein isothiocyanate; PE, phycoerythrin.

(Fig. 1A). Rat BM-MSCs were successfully established in culture and proliferated in vitro. Morphological and phenotypic examination revealed that BM-MSCs were confirmed to be plastic-adherent cells with a spindle-shaped morphology under standard culture conditions, as determined by microscopy, and some of the cells exhibited a whirlpool or chrysanthemum pattern (Fig. 1B). BM-MSCs were incubated with antibodies against CD29, CD90, RT1A, CD34, RT1B and CD45, and were analyzed by flow cytometry. Phenotypic examination of BM-MSCs at passage 3 demonstrated that 97.0\% of cells expressed CD29, 96.3\% of cells expressed CD90, and 96.3\% of cells expressed RT1A (Fig. 1C-E). By contrast, $>95 \%$ of BM-MSCs were negative for CD34, CD45 and RT1B (Fig. 1C-E), which was in accordance with the results of a previous study (26).

Detection of liver enzymes in supernatants. When co-cultured with xenogeneic SLCs or BM-MSCs, no significant difference in liver enzyme levels in HepG2.2.15 cell supernatants was observed (Table II). This suggested that neither BM-MSCs nor SLCs induced rejection of the human hepatocellular carcinoma cell line, HepG2.2.15.

Effects of BM-MSCs on the activity of SLCs and HepG2.2.15 cells. The viability of SLCs in group 5 was significantly lower when compared with that of group 4 at each time point $(24 \mathrm{~h}$, $\mathrm{P}<0.05 ; 48$ h, $\mathrm{P}<0.01 ; 72$ h, $\mathrm{P}<0.01$; Fig. 2A), which suggested that BM-MSCs may reduce the viability of SLCs.

The viability of adherent cells in group 3 was significantly lower when compared to that of groups 2 at 48 and $72 \mathrm{~h}$, respectively ( $\mathrm{P}<0.01$ at 48 and $72 \mathrm{~h}$; Fig. 2B). These results suggested that BM-MSCs may inhibit the viability of HepG2.2.15 cells. In contrast, the viability of adherent cells in group 5 was significantly higher when compared to that of groups 3 at 24,48 and
$72 \mathrm{~h}$, respectively $(\mathrm{P}<0.01$ at 24,48 and $72 \mathrm{~h}$; Fig. 2B). These results suggested that BM-MSCs exhibited stimulatory effects on HepG2.2.15 cell viability when co-cultured with SLCs.

Effects of BM-MSCs on the supernatant levels of HBV DNA in HepG2.2.15 cells. The quantity of supernatant HBV DNA in group 5 was significantly lower when compared to that of groups 2, 3 and 4 at 24, 48 and $72 \mathrm{~h}$, respectively (Fig. 3A).

When co-cultured with BM-MSCs and SLCs (group 5), the intracellular quantity of HBV cccDNA in HepG2.2.15 cells was lower than that of groups 2 and 4 at $24 \mathrm{~h}$, however this did not reach statistical significance. The intracellular quantity of HBV cccDNA in group 5 was statistically higher than that of group 2 at $72 \mathrm{~h}(\mathrm{P}<0.01$; Fig. 3B). The intracellular quantity HBV cccDNA in group 5 was significantly lower than that of groups 2, 3 and 4 at $48 \mathrm{~h}$ (Fig. 3B). These findings suggested that BM-MSCs and SLCs may inhibit HBV replication in HepG2.2.15 cells, and that the inhibitory effect was more significant when HepG2.2.15 cells were co-cultured with BM-MSCs and SLCs.

Detection of intracellular HBV cccDNA in BM-MSCs. No intracellular HBV cccDNA was detected in the BM-MSCs in any of the groups (data not shown), which suggested that BM-MSCs co-cultured with HepG2.2.15 cells were not be infected by HBV.

$H B V$ gene sequencing. No mutations in the $\mathrm{C}$ or $\mathrm{X}$ regions of the HBV genome were detected in HepG2.2.15 cells co-cultured with BM-MSCs, SLCs, or both types of cells (Table III). However, a T45 N mutation in the $\mathrm{S}$ region, and an rtR192S mutation in the P region was identified in the supernatants of BM-MSCs + HepG2.2.15 and SLCs + HepC2.2.15 groups, respectively (Table III). 
Table II. Supernatant ALT and AST levels in different groups at different time points.

\begin{tabular}{lcccccccc}
\hline & \multicolumn{2}{c}{$24 \mathrm{~h}$} & & \multicolumn{2}{c}{$48 \mathrm{~h}$} & & \multicolumn{2}{c}{$72 \mathrm{~h}$} \\
\cline { 2 - 3 } Group & ALT (IU/l) & AST (IU/l) & & ALT (IU/l) & AST (IU/l) & & ALT (IU/l) & AST (IU/l) \\
\hline HepG2.2.15 & $1.17 \pm 0.41$ & $9.53 \pm 1.63$ & & $1.50 \pm 0.38$ & $13.25 \pm 2.65$ & & $1.47 \pm 0.27$ & $19.82 \pm 1.64$ \\
BM-MSCs+HepG2.2.15 & $1.20 \pm 0.36$ & $11.30 \pm 0.40$ & & $1.40 \pm 0.33$ & $15.65 \pm 1.02$ & & $1.77 \pm 0.59$ & $23.12 \pm 2.22$ \\
SLCs+HepG2.2.15 & $1.45 \pm 0.37$ & $11.02 \pm 2.95$ & & $1.72 \pm 0.20$ & $17.62 \pm 3.26$ & & $1.83 \pm 0.43$ & $23.42 \pm 3.49$ \\
SLCs+BM-MSCs+HepG2.2.15 & $1.17 \pm 0.40$ & $11.70 \pm 3.37$ & & $1.43 \pm 0.14$ & $15.93 \pm 0.68$ & & $1.73 \pm 0.19$ & $21.27 \pm 0.74$ \\
P-value & 0.442 & 0.099 & & 0.862 & 0.447 & & 0.056 & 0.145
\end{tabular}

All values are presented as the mean \pm standard deviation $(n=3)$. ALT, alanine transaminase; AST, aspartate transaminase; BM-MSC, bone marrow-derived mesenchymal stem cells; SLC, splenic lymphocytes; IU, intentional unit.
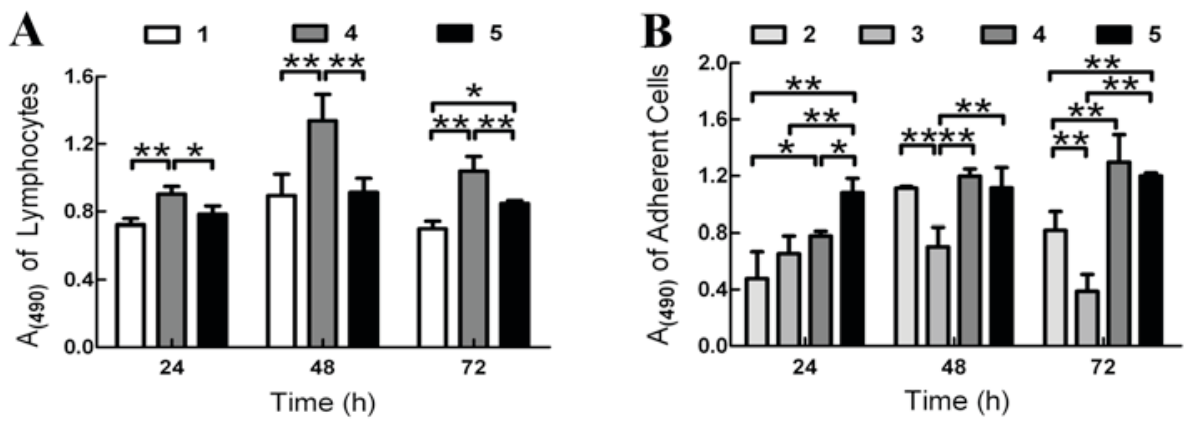

Figure 2. Viability of SLCs and adherent cells as determined using the MTT assay. The viability of (A) SLCs in groups 1, 4 and 5, and (B) adherent cells in groups 2, 3, 4 and 5. "P $<0.05$ and ${ }^{* *} \mathrm{P}<0.01$ as indicated. SLCs, splenic lymphocytes; 1, SLCs alone; 2, HepG2.2.15 cells alone; 3, bone marrow-derived mesenchymal stem cells (BM-MSCs) + HepG2.2.15 cells; 4, SLCs + HepG2.2.15 cells; 5, SLCs + BM-MSCs + HepG2.2.15 cells.
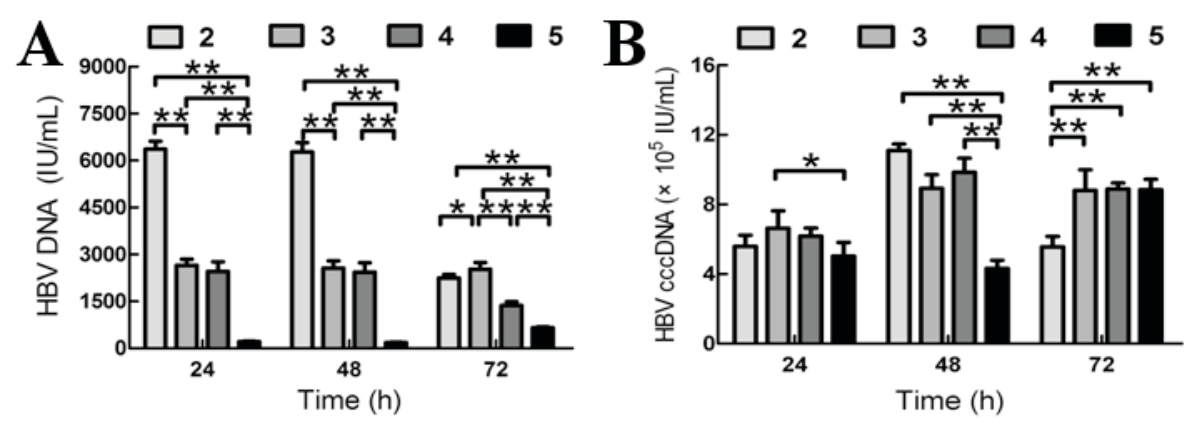

Figure 3. Supernatant HBV DNA quantities and intracellular covalently cccDNA levels. The levels of (A) supernatant HBV DNA and (B) HBV cccDNA in cells from groups $2-5$. ${ }^{*} \mathrm{P}<0.05$ and ${ }^{* *} \mathrm{P}<0.01$ as indicated. HBV, hepatitis B virus; cccDNA, covalently closed circular DNA; IU, international unit; 2 , HepG2.2.15 cells; 3, bone marrow-derived mesenchymal stem cells (BM-MSCs) + HepG2.2.15 cells; 4, splenic lymphocytes (SLCs) + HepG2.2.15 cells; 5 , SLCs + BM-MSCs + HepG2.2.15 cells.

Effect of BM-MSCs on lymphocyte subsets. Detection of lymphocyte surface markers by flow cytometry revealed that the percentage of $\mathrm{CD}^{+} \mathrm{CD} 4^{+}$cells in group 5 was higher than that of group 4 at 24 and $72 \mathrm{~h}$, but was lower at $48 \mathrm{~h}$. These differences did not reach statistical significance (Fig. 4A).

The percentage of $\mathrm{CD}^{+} \mathrm{CD} 8^{+}$cells in group 5 was significantly lower than that of group 4 at all time points ( 24 h, $\mathrm{P}<0.01 ; 48$ h, $\mathrm{P}<0.05 ; 72$ h, $\mathrm{P}<0.05$; Fig. 4B). When compared with group 4 , the $\mathrm{CD}^{+} \mathrm{CD} 4^{+} / \mathrm{CD}^{+} \mathrm{CD}^{+}$ratio in group 5 significantly increased at 24 and $48 \mathrm{~h}(\mathrm{P}<0.01$ and $\mathrm{P}<0.05$, respectively; Fig. $4 \mathrm{C}$ ), but no significant difference was observed at $72 \mathrm{~h}$. The percentage of $\mathrm{CD} 3^{+} \mathrm{CD} 8^{+}$cells was positively correlated with HBV DNA levels when co-cultured with BM-MSCs $(24 \mathrm{~h}, r=0.865 ; 48 \mathrm{~h}, r=0.766 ; 72 \mathrm{~h}, r=0.912$; $\mathrm{P}<0.05)$.

Effect of BM-MSCs on cytokine levels in co-cultured SLCs and HepG2.2.15 cell supernatants. The supernatant concentrations of IFN- $\gamma$ in group 5 were higher than those of groups 3 and 4 at 24, 48 and 72 h (Table IV). By contrast, IL-10 and IL-22 levels in group 5 were lower than those of group 3 and group 4 at 24, 48 and $72 \mathrm{~h}$ (Table IV). IFN- $\gamma$ secretion 
Table III. Effect of BM-MSCs and SLCs on the HBV gene sequence.

\begin{tabular}{lllll}
\hline & \multicolumn{3}{c}{ HBV gene sequence } & \\
\cline { 2 - 5 } Group & $\begin{array}{c}\text { Mutation in } \\
\text { C region }\end{array}$ & $\begin{array}{c}\text { Mutation in } \\
\text { X region }\end{array}$ & $\begin{array}{c}\text { Mutation in } \\
\text { S region }\end{array}$ & $\begin{array}{c}\text { Mutation in } \\
\text { P region }\end{array}$ \\
\hline HepG2.2.15 & No mutation & No mutation & No mutation & No mutation \\
BM-MSCs+HepG2.2.15 & No mutation & No mutation & T45N & No mutation \\
SLCs+HepG2.2.15 & No mutation & No mutation & No mutation & rtR192S \\
SLCs+BM-MSCs+HepG2.2.15 & No mutation & No mutation & No mutation & No mutation
\end{tabular}

BM-MSCS, bone marrow-derived mesenchymal stem cells; SLCs, splenic lymphocytes; HBV, hepatitis B virus.
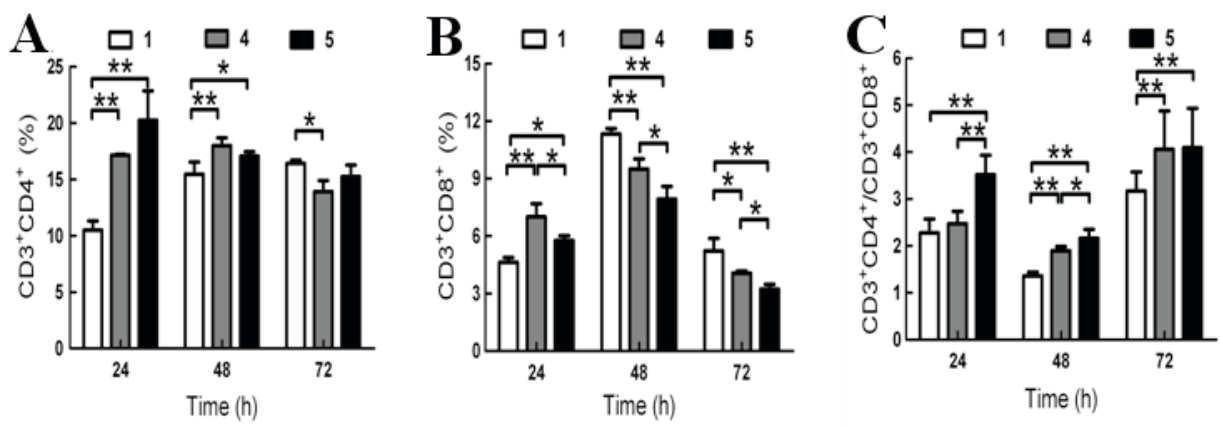

Figure 4. Lymphocyte cell surface markers. The percentage of (A) $\mathrm{CD}^{+} \mathrm{CD} 4^{+}$, (B) $\mathrm{CD} 3^{+} \mathrm{CD} 8^{+}$, and $(\mathrm{C}) \mathrm{CD} 3^{+} \mathrm{CD} 4^{+} / \mathrm{CD} 3^{+} \mathrm{CD} 8^{+}$cells as determined by flow cytometry analysis. ${ }^{*} \mathrm{P}<0.05$ and ${ }^{* * *} \mathrm{P}<0.01$ as indicated. 1, Splenic lymphocytes (SLCs); 4, SLCs + HepG2.2.15 cells; 5, SLCs + bone marrow-derived mesenchymal stem cells (BM-MSCs) + HepG2.2.15 cells.

levels were negatively correlated with HBV DNA levels $(24 \mathrm{~h}$, $r=-0.900,48 \mathrm{~h}, r=-0.982 ; 72 \mathrm{~h}, r=-0.968 ; \mathrm{P}<0.05)$, whereas IL-10 and IL-22 secretion levels were positively correlated with HBV DNA levels (IL-10, $24 \mathrm{~h}, r=0.860 ; 48 \mathrm{~h}, r=0.972$; $\mathrm{P}<0.05 ;$ IL-22, $48 \mathrm{~h}, r=0.858 ; 72 \mathrm{~h}, r=0.742 ; \mathrm{P}<0.05)$. In group 5 , the supernatant IFN- $\gamma$ levels at $48 \mathrm{~h}$ were significantly higher than those at $72 \mathrm{~h}$, and the supernatant levels of IL-10 at $48 \mathrm{~h}$ were significantly lower than those detected at 24 and $72 \mathrm{~h}$ (Table IV). These findings suggested that alterations in IFN- $\gamma$ and IL-10 levels were most evident at $48 \mathrm{~h}$ within the same group.

\section{Discussion}

Liver-derived MSCs have been demonstrated to be crucial for the repair of damaged hepatocytes and liver regeneration (27-29). Oh et al (30) confirmed that BM-MSCs are potential sources of hepatic oval cells. When the liver is severely damaged, BM-MSCs differentiate into hepatic progenitor-like cells and mediate repair of the liver (31-33). The present study aimed to explore the effects of BM-MSCs on hepatocytes infected with HBV. Previous studies have demonstrated that human MSCs survive and exhibit protective effects on neurological and lung injuries following transplantation into rats (34-36). However, they may also stimulate an allogeneic immune response to increase lymphocyte proliferation in the host $(37,38)$. Therefore, with the lack of stable rat cell lines transfected with HBV, and the strict ethical limits to acquire human stem cells, a xenotransplantation model was employed in the present study.
The preliminary findings demonstrated that when co-cultured with BM-MSCs, the proliferation of HepG2.2.15 cells was inhibited and HBV DNA levels were decreased. When BM-MSCs were co-cultured with SLCs, HBV DNA levels were markedly reduced. Meanwhile, BM-MSCs induced very few HBV genome sequence mutations and did not cause rejection between xenogeneic cells. To the best of our knowledge the T45N mutation in the $\mathrm{S}$ region, and the rtR192S mutation in the $\mathrm{P}$ region, are not known to be significant in the clinical treatment of hepatitis B. In addition, the preliminary results of the present study suggested that BM-MSCs may inhibit the replication of HBV cccDNA in vitro. It is possible that BM-MSCs may suppress the proliferation of co-cultured $\mathrm{T}$ cells in vitro, thereby inhibiting immune responses to induce immune tolerance (39-41). Alternatively, BM-MSCs may secrete cytokines, including fibroblast growth factor $(42,43)$, epidermal growth factor (EGF) (44), and hepatocyte growth factor (HGF) $(43,45,46)$ to inhibit HBV replication (47). In addition, intracellular HBV cccDNA in BM-MSCs co-cultured with HepG2.2.15 cells was not detected, which supports the conclusion that HBV is unable to replicate in BM-MSCs $(48,49)$.

BM-MSCs are a cell type that exert immunomodulatory activities (19-21). They inhibit the proliferation and activation of $\mathrm{T}$ cells and exhibit immunomodulatory functions mediated by soluble factors $(39,41)$. Prostaglandin $\mathrm{E}_{2}\left(\mathrm{PGE}_{2}\right)$ and indoleamine dioxygenase were observed to be potentially involved in the immunomodulatory function of BM-MSCs (50). The majority of $\mathrm{T}$ lymphocytes can be divided into $\mathrm{CD} 4^{+} \mathrm{T}$ cells 
Table IV. Cytokine levels in cell culture supernatants.

\begin{tabular}{lllll}
\hline Cytokine & \multicolumn{1}{c}{ Group } & $24 \mathrm{~h}(\mathrm{pg} / \mu \mathrm{l})$ & $48 \mathrm{~h}(\mathrm{pg} / \mu \mathrm{l})$ & $72 \mathrm{~h}(\mathrm{pg} / \mu \mathrm{l})$ \\
\hline IFN- $\gamma$ & SLCs & $848.557 \pm 11.409^{\mathrm{aa}}$ & $468.347 \pm 20.523^{\text {aa }}$ & $528.111 \pm 15.640^{\text {aa }}$ \\
& BM-MSCs+HepG2.2.15 & $636.650 \pm 47.047^{\text {aa }}$ & $460.953 \pm 38.345^{\text {aa }}$ & $603.735 \pm 26.848^{\text {a }}$ \\
& SLCs+HepG2.2.15 & $675.637 \pm 19.046^{\text {aa }}$ & $621.237 \pm 24.709^{\text {aa }}$ & $517.170 \pm 31.331^{\text {aa }}$ \\
& SLCs+BM-MSCs+HepG2.2.15 & $735.030 \pm 18.646$ & $780.463 \pm 19.879$ & $676.317 \pm 34.414^{\text {bb }}$ \\
IL-10 & SLCs & $803.930 \pm 55.897^{\text {aa }}$ & $297.040 \pm 32.246^{\text {aa }}$ & $183.367 \pm 46.742^{\text {aa }}$ \\
& BM-MSCs+HepG2.2.15 & $240.747 \pm 28.605^{\text {aa }}$ & $206.609 \pm 13.669^{\text {a }}$ & $259.580 \pm 30.070^{\text {aa }}$ \\
& SLCs+HepG2.2.15 & $511.553 \pm 37.490^{\mathrm{a}}$ & $413.360 \pm 14.133^{\text {aa }}$ & $553.133 \pm 54.416^{\text {a }}$ \\
IL-22 & SLCs+BM-MSCs+HepG2.2.15 & $420.227 \pm 23.235^{\text {bb }}$ & $153.087 \pm 26.016$ & $447.230 \pm 31.192^{\text {bb }}$ \\
& SLCs & $344.423 \pm 36.904^{\text {aa }}$ & $180.337 \pm 4.672^{\text {aa }}$ & $164.537 \pm 35.654$ \\
& BM-MSCs+HepG2.2.15 & $183.135 \pm 18.123^{\mathrm{a}}$ & $166.264 \pm 23.206^{\text {aa }}$ & $164.722 \pm 12.389$ \\
& SLCs+HepG2.2.15 & $166.337 \pm 18.651$ & $258.923 \pm 23.426^{\text {aa }}$ & $305.053 \pm 14.766^{\text {aa }}$ \\
& SLCs+BM-MSCs+HepG2.2.15 & $146.007 \pm 20.407^{\text {bb }}$ & $208.537 \pm 6.499$ & $210.857 \pm 22.527$ \\
\hline
\end{tabular}

Data are presented as the mean \pm standard deviation $(\mathrm{n}=3) .{ }^{\mathrm{a}} \mathrm{P}<0.05$, and ${ }^{\text {aa }} \mathrm{P}<0.01$, vs. SLCs $+\mathrm{BM}-\mathrm{MSCs}+\mathrm{HepG} 2.2 .15$. ${ }^{\mathrm{b}} \mathrm{P}<0.05$, and ${ }^{\text {bb }} \mathrm{P}<0.01$, vs. the same group at $48 \mathrm{~h}$. IFN- $\gamma$, interferon- $\gamma$; IL, interleukin; SLCs, splenic lymphocytes; BM-MSCs, bone marrow-derived mesenchymal stem cells.

and $\mathrm{CD}^{+} \mathrm{T}$ cells, and the majority of $\mathrm{CD}^{+} \mathrm{T}$ cells are cytotoxic T lymphocytes (CTL). T cell function is exhausted during chronic HBV infection, and CTLs cannot effectively eliminate the virus. As a result, the virus persists and the proportion of $\mathrm{T}$ cell subsets in the peripheral blood is subsequently altered (51-53). The findings of the present study suggested that the percentage of $\mathrm{CD}^{+}$cells was positively correlated with HBV DNA levels, which is consistent with a previous study demonstrating that an imbalance of $\mathrm{T}$ cell subsets was closely associated with HBV DNA levels $(54,55)$. The $\mathrm{CD}^{+} / \mathrm{CD}^{+}$ ratio increased at 24 and $48 \mathrm{~h}$, and then decreased at $72 \mathrm{~h}$. Furthermore, the reduction in the levels of intracellular HBV cccDNA was the most significant at $48 \mathrm{~h}$, which suggested that the increased $\mathrm{CD} 4^{+} / \mathrm{CD} 8^{+}$ratio was correlated with inhibitory effects on HBV cccDNA replication. To further confirm these results, the levels of cytokines were measured.

MSCs clearly inhibit the proliferation of allogeneic lymphocytes, and immunosuppression is mediated by $\mathrm{CD}^{+}$regulatory cells (56). $\mathrm{CD}^{+}$cells are divided into the $\mathrm{Tc} 1$ and $\mathrm{Tc} 2$ subtypes, and control of the $\mathrm{Tc} 1 / \mathrm{Tc} 2$ cell ratio is necessary to maintain normal immune function $(57,58)$. Therefore, IFN- $\gamma$ and IL-10 cytokine levels were ascertained in the present study, as they are secreted by $\mathrm{Tc} 1$ and $\mathrm{Tc} 2$ cells, respectively. The results demonstrated that BM-MSCs may influence the expression of IFN- $\gamma$ and IL-10 by inhibiting CD8 ${ }^{+} \mathrm{T}$ cells, as well as inhibit the replication and reduce the levels of HBV DNA.

BM-MSCs secrete various cytokines that affect the function of hematopoietic cells, and release a number of neurotrophic factors, including nerve growth factor, EGF, ciliary neurotrophic factor and IFN- $\gamma$ (59). The IFN- $\gamma$ cytokine induces BM-MSCs to constitutively express increased levels of immunosuppressive cytokines, such as $\mathrm{PGE}_{2}, \mathrm{HGF}$, and transforming growth factor (TGF)- $\beta 1$ (60). Thus, the cytokine expression results obtained in the current study indicate that BM-MSCs may secrete cytokines that affect HBV. However, testing this hypothesis will require further study.
IL-22 was first discovered in the year 2000 (61). As it demonstrates $22 \%$ amino acid sequence similarity with IL-10, it was classified as an IL-10 family member (61). However, whether IL-22 exhibits anti- or pro-inflammatory effects on HBV infection remains controversial. Previous studies have demonstrated that intra-hepatic expression of IL-22 was increased in patients with acute and chronic hepatitis B (62). When infected with the virus, $\mathrm{T}$ cells mediate antiviral immunity, and cause inflammatory injury to the liver. Meanwhile, inflammation and injury leads to compensatory increases in levels of cytokines (e.g. IL-22) that may protect hepatocytes from inflammation and repair liver damage (63). The results of the present study indicated that IL-22 and IL-10 secretion were reduced significantly when SLCs were co-cultured with BM-MSCs, which suggested that IL-22 exerted anti-inflammatory effects in HBV infection.

HBV-associated end-stage liver disease poses a serious threat to human health, and liver transplantation is currently the only effective treatment. BM-MSC transplantation has been proposed as a novel strategy for the treatment of $\mathrm{HBV}$, and may represent a new method for prophylaxis and the treatment of HBV re-infection following liver transplantation. In addition, studies of the effects of BM-MSCs on HBV cccDNA levels may provide novel strategies to screen for preventative treatments against HBV re-infection. Although HBV does not affect the phenotype or differentiation ability of BM-MSCs, it has been demonstrated to inhibit the proliferation of BM-MSCs in vitro (64). Therefore, a number of issues require further investigation before BM-MSCs may be used as a clinical treatment option, and will be a focus of future research.

\section{Acknowledgements}

The present study was supported by the National Natural Science Foundation of China (grant nos. 81270528, 81170444, 
81441022 and 81670574) and the Natural Science Foundation of Tianjin (grant nos. 08JCYBJC08400, 11JCZDJC27800 and 12JCZDJC25200), and the Technology Foundation of Health Bureau in Tianjin (grant nos. 2011KY11 and 10KG101).

\section{References}

1. Zhuang H: Current status and goals of hepatitis B prevention and treatment. Zhonghua Nei Ke Za Zhi 47: 793-795, 2008 (In Chinese).

2. Shen Zhong-Yang, Zhu Zhi-Jun, Deng Yong-Lin, Sun Liying, Qu Wei, Rao Wei, Sun Xiao-Ye, Zheng Hong, Pan Cheng and Liu Yi-He: Combination of low-dose HBIg and Nucleoside analogues to prevent recurrent hepatitis B virus after liver transplantation: A retrospective analysis of 1506 cases. Chinese J Hepatobiliary Surg 17: 364-366, 2011.

3. Avolio AW, Nure E, Pompili M, Barbarino R, Basso M, Caccamo L, Magalini S, Agnes S and Castagneto M: Liver transplantation for hepatitis B virus patients: Long-term results of three therapeutic approaches. Transplant Proc 40: 1961-1964, 2008.

4. Samuel D, Feray C and Bismuth H: Hepatitis viruses and liver transplantation. J Gastroenterol Hepatol 12 (Suppl): S335-S341, 1997.

5. Campsen J, Zimmerman M, Trotter J, Hong J, Freise C, Brown R, Cameron A, Ghobrial M, Kam I, Busuttil R, et al: Liver transplantation for hepatitis B liver disease and concomitant hepatocellular carcinoma in the United States with hepatitis B immunoglobulin and nucleoside/nucleotide analogues. Liver Transpl 19: 1020-1029, 2013.

6. Cholongitas E, Goulis J, Akriviadis E and Papatheodoridis GV: Hepatitis B immunoglobulin and/or nucleos(t)ide analogues for prophylaxis against hepatitis b virus recurrence after liver transplantation: A systematic review. Liver Transpl 17: 1176-1190, 2011.

7. Ishigami M, Onishi Y, Ito T, Katano Y, Ito A, Hirooka Y, Kiuchi T and Goto H: Anti-hepatitis B surface immunoglobulin reduction in early postoperative period after liver transplantation in hepatitis B virus-positive patients. Hepatol Res 41: 1189-1198, 2011.

8. Saab S, Ham MY, Stone MA, Holt C and Tong M: Decision analysis model for hepatitis B prophylaxis one year after liver transplantation. Liver Transpl 15: 413-420, 2009.

9. Shen ZY, Zheng WP, Deng YL and Song HL: Variations in the S and $\mathrm{P}$ regions of the hepatitis $\mathrm{B}$ virus genome under immunosuppression in vitro and in vivo. Viral Immunol 25: 368-378, 2012.

10. Limquiaco JL, Wong J, Wong VW, Wong GL, Tse CH, Chan HY, Kwan KY, Lai PB and Chan HL: Lamivudine monoprophylaxis and adefovir salvage for liver transplantation in chronic hepatitis B: A seven-year follow-up study. J Med Virol 81: 224-229, 2009.

11. Rosenau J, Hooman N, Hadem J, Rifai K, Bahr MJ, Philipp G, Tillmann HL, Klempnauer J, Strassburg CP and Manns MP Failure of hepatitis B vaccination with conventional $\mathrm{HbsAg}$ vaccine in patients with continuous HBIG prophylaxis after liver transplantation. Liver Transpl 13: 367-373, 2007.

12. Wursthorn K, Wedemeyer $\mathrm{H}$ and Manns MP: Managing HBV in patients with impaired immunity. Gut 59: 1430-1445, 2010.

13. Han D, Wu C, Xiong Q, Zhou L and Tian Y: Anti-inflammatory mechanism of bone marrow mesenchymal stem cell transplantation in rat model of spinal cord injury. Cell Biochem Biophys 71: 1341-1347, 2015

14. Shen ZY, Zhang J, Song HL and Zheng WP: Bone-marrow mesenchymal stem cells reduce rat intestinal ischemia-reperfusion injury, ZO-1 downregulation and tight junction disruption via a TNF- $\alpha$-regulated mechanism. World J Gastroenterol 19: 3583-3595, 2013.

15. Mitkari B, Nitzsche F, Kerkelä E, Kuptsova K, Huttunen J, Nystedt J, Korhonen M and Jolkkonen J: Human bone marrow mesenchymal stem/stromal cells produce efficient localization in the brain and enhanced angiogenesis after intra-arterial delivery in rats with cerebral ischemia, but this is not translated to behavioral recovery. Behav Brain Res 259: 50-59, 2014.

16. Santhakumar R, Vidyasekar P and Verma RS: Cardiogel: A nano-matrix scaffold with potential application in cardiac regeneration using mesenchymal stem cells. PLoS One 9: e114697, 2014.

17. Ball LM, Bernardo ME, Roelofs H, Lankester A, Cometa A Egeler RM, Locatelli F and Fibbe WE: Cotransplantation of ex vivo expanded mesenchymal stem cells accelerates lymphocyte recovery and may reduce the risk of graft failure in haploidentical hematopoietic stem-cell transplantation. Blood 110: 2764-2767, 2007.
18. Phinney DG and Prockop DJ: Concise review: Mesenchymal stem/multipotent stromal cells: The state of transdifferentiation and modes of tissue repair-current views. Stem Cells 25: 2896-2902, 2007.

19. Zhang W, Shen ZY, Song HL, Yang Y, Wu BJ, Fu NN and Liu T: Protective effect of bone marrow mesenchymal stem cells in intestinal barrier permeability after heterotopic intestinal transplantation. World J Gastroenterol 20: 7442-7451, 2014.

20. Perez-Basterrechea M, Obaya AJ, Meana A, Otero J and Esteban MM: Cooperation by fibroblasts and bone marrowmesenchymal stem cells to improve pancreatic rat-to-mouse islet xenotransplantation. PLoS One 8: e73526, 2013.

21. Roemeling-van Rhijn M, Khairoun M, Korevaar SS, Lievers E, Leuning DG, Ijzermans JN, Betjes MG, Genever PG, van Kooten C, de Fijter HJ, et al: Human bone marrow- and adipose tissue-derived mesenchymal stromal cells are immunosuppressive in vitro and in a humanized allograft rejection model. J Stem Cell Res Ther (Suppl 6): S20780, 2013.

22. Shi M, Zhang Z, Xu R, Lin H, Fu J, Zou Z, Zhang A, Shi J, Chen L, Lv S, et al: Human mesenchymal stem cell transfusion is safe and improves liver function in acute-on-chronic liver failure patients. Stem Cells Transl Med 1: 725-731, 2012.

23. Sells MA, Chen ML and Acs G: Production of hepatitis B virus particles in Hep G2 cells transfected with cloned hepatitis B virus DNA. Proc Natl Acad Sci USA 84: 1005-1009, 1987.

24. Shen ZY, Zheng WP, Liu T, Yang Y and Song HL: Effects of dendritic cells from hepatitis B virus transgenic mice-stimulated autologous lymphocytes on hepatitis B virus replication: A study on the impact of specific sensitized effector cells on in vitro virus replication. Viral Immunol 28: 85-92, 2015.

25. Gao YT, Han T, Li Y, Yang B, Wang YJ, Wang FM, Jing X and Du Z: Enhanced specificity of real-time PCR for measurement of hepatitis $\mathrm{B}$ virus cccDNA using restriction endonuclease and plasmid-safe ATP-dependent DNase and selective primers. J Virol Methods 169: 181-187, 2010.

26. Harting M, Jimenez F, Pati S, Baumgartner J and Cox C Jr: Immunophenotype characterization of rat mesenchymal stromal cells. Cytotherapy 10: 243-253, 2008.

27. Joshi M, B Patil P, He Z, Holgersson J, Olausson M and Sumitran-Holgersson S: Fetal liver-derived mesenchymal stromal cells augment engraftment of transplanted hepatocytes. Cytotherapy 14: 657-669, 2012.

28. Fouraschen SM, Pan Q, de Ruiter PE, Farid WR, Kazemier G, Kwekkeboom J, Ijzermans JN, Metselaar HJ, Tilanus HW, de Jonge J and van der Laan LJ: Secreted factors of human liver-derived mesenchymal stem cells promote liver regeneration early after partial hepatectomy. Stem Cells Dev 21: 2410-2419, 2012.

29. Fouraschen SM, Hall SR, de Jonge J and van der Laan LJ: Support of hepatic regeneration by trophic factors from liver-derived mesenchymal stromal/stem cells. Methods Mol Biol 1213: 89-104, 2014

30. Oh SH, Hatch HM and Petersen BE: Hepatic oval 'stem' cell in liver regeneration. Semin Cell Dev Biol 13: 405-409, 2002.

31. Facciorusso A, Antonino M, Del Prete V, Neve V, Scavo MP and Barone M: Are hematopoietic stem cells involved in hepatocarcinogenesis? Hepatobiliary Surg Nutr 3: 199-206, 2014.

32. Lehwald N, Duhme C, Wildner M, Kuhn S, Fürst G, Forbes SJ, Jonas S, Robson SC, Knoefel WT, Schmelzle M and Schulte Am Esch J: HGF and SDF-1-mediated mobilization of CD133+ BMSC for hepatic regeneration following extensive liver resection. Liver Int 34: 89-101, 2014.

33. Zocco MA, Piscaglia AC, Giuliante F, Arena V, Novi M, Rinninella E, Tortora A, Rumi C, Nuzzo G, Vecchio FM, et al: $\mathrm{CD} 133+$ stem cell mobilization after partial hepatectomy depends on resection extent and underlying disease. Dig Liver Dis 43: 147-154, 2011.

34. Hosseini M, Moghadas M, Edalatmanesh MA and Hashemzadeh MR: Xenotransplantation of human adipose derived mesenchymal stem cells in a rodent model of Huntington's disease: Motor and non-motor outcomes. Neurol Res 37: 309-319, 2015.

35. Gao F, Li Q, Hou L, Li Z, Min F and Liu Z: Mesenchymal stem cell-based angiotensin-converting enzyme 2 in treatment of acute lung injury rat induced by bleomycin. Exp Lung Res 40: 392-403, 2014.

36. Khabbal J, Kerkelä E, Mitkari B, Raki M, Nystedt J, Mikkonen V, Bergström K, Laitinen S, Korhonen M and Jolkkonen J. Differential clearance of rat and human bone marrow-derived mesenchymal stem cells from the brain after intra-arterial infusion in rats. Cell Transplant 24: 819-828, 2015. 
37. Chuang CK, Lin KJ, Lin CY, Chang YH, Yen TC, Hwang SM, Sung LY, Chen HC and Hu YC: Xenotransplantation of human mesenchymal stem cells into immunocompetent rats for calvarial bone repair. Tissue Eng Part A 16: 479-488, 2010.

38. Wang Y, Chen X, Armstrong MA and Li G: Survival of bone marrow-derived mesenchymal stem cells in a xenotransplantation model. J Orthop Res 25: 926-932, 2007.

39. Jorgensen C, Djouad F, Apparailly F and Noël D: Engineering mesenchymal stem cells for immunotherapy. Gene Ther 10 928-931, 2003

40. Kong QF, Sun B, Wang GY, Zhai DX, Mu LL, Wang DD, Wang JH, Li R and Li HL: BM stromal cells ameliorate experimental autoimmune myasthenia gravis by altering the balance of Th cells through the secretion of IDO. Eur J Immunol 39: 800-809, 2009

41. Wang Q, Sun B, Wang D, Ji Y, Kong Q, Wang G, Wang J, Zhao W, Jin L and Li H: Murine bone marrow mesenchymal stem cells cause mature dendritic cells to promote T-cell tolerance. Scand J Immunol 68: 607-615, 2008.

42. Liu Y, Ming L, Luo H, Liu W, Zhang Y, Liu H and Jin Y: Integration of a calcined bovine bone and BMSC-sheet 3D scaffold and the promotion of bone regeneration in large defects Biomaterials 34: 9998-10006, 2013.

43. Hiwatashi N, Hirano S, Mizuta M, Tateya I, Kanemaru S, Nakamura $T$ and Ito $\mathrm{J}$ : Adipose-derived stem cells versus bone marrow-derived stem cells for vocal fold regeneration. Laryngoscope 124: E461-E469, 2014.

44. Kwon DS, Gao X, Liu YB, Dulchavsky DS, Danyluk AL, Bansal M, Chopp M, McIntosh K, Arbab AS, Dulchavsky SA and Gautam SC: Treatment with bone marrow-derived stromal cells accelerates wound healing in diabetic rats. Int Wound J 5: 453-463, 2008

45. Sun L, Fan X, Zhang L, Shi G, Aili M, Lu X, Jiang T and Zhang Y: Bone mesenchymal stem cell transplantation via four routes for the treatment of acute liver failure in rats. Int J Mol Med 34: 987-996, 2014

46. Li T, Zhu J, Ma K, Liu N, Feng K, Li X, Wang S and Bie P: Autologous bone marrow-derived mesenchymal stem cell transplantation promotes liver regeneration after portal vein embolization in cirrhotic rats. J Surg Res 184: 1161-1173, 2013.

47. Schorr O, Borel C, Trepo C, Zoulim F and Hantz O: Effects of liver growth factors on hepadnavirus replication in chronically infected duck hepatocytes. J Hepatol 44: 842-847, 2006.

48. Xie C, Zheng YB, Zhu HP, Peng L and Gao ZL: Human bone marrow mesenchymal stem cells are resistant to HBV infection during differentiation into hepatocytes in vivo and in vitro. Cell Biol Int 33: 493-500, 2009.

49. Rong Q, Zhang L, Su E, Li J, Li J, Liu Z, Huang Z, Ma W, Cao K and Huang J: Bone marrow-derived mesenchymal stem cells are capable of mediating hepatitis B virus infection in injured tissues. J Viral Hepat 15: 607-614, 2008.

50. Matysiak M, Orlowski W, Fortak-Michalska M, Jurewicz A and Selmaj K: Immunoregulatory function of bone marrow mesenchymal stem cells in EAE depends on their differentiation state and secretion of PGE2. J Neuroimmunol 233: 106-111, 2011.
51. Conroy MJ, Mac Nicholas R, Grealy R, Taylor M, Otegbayo JA, O'Dea S, Mulcahy F, Ryan T, Norris S and Doherty DG: Circulating CD56dim natural killer cells and CD56+ T cells that produce interferon- $\gamma$ or interleukin-10 are expanded in asymptomatic, $\mathrm{E}$ antigen-negative patients with persistent hepatitis $\mathrm{B}$ virus infection. J Viral Hepat 22: 335-345, 2015.

52. Murray JM and Goyal A: In silico single cell dynamics of hepatitis B virus infection and clearance. J Theor Biol 366: 91-102, 2015.

53. Ito $\mathrm{H}$, Ando $\mathrm{T}$, Ando $\mathrm{K}$, Ishikawa $\mathrm{T}$, Saito $\mathrm{K}$, Moriwaki $\mathrm{H}$ and Seishima M: Induction of hepatitis B virus surface antigen-specific cytotoxic T lymphocytes can be up-regulated by the inhibition of indoleamine 2,3-dioxygenase activity. Immunology 142: 614-623, 2014.

54. Xue-Song L, Cheng-Zhong L, Ying Z and Mo-Bin W: Changes of Treg and Th17 cells balance in the development of acute and chronic hepatitis B virus infection. BMC Gastroenterol 12: 43, 2012.

55. Zhang JY, Song CH, Shi F, Zhang Z, Fu JL and Wang FS: Decreased ratio of Treg cells to Th17 cells correlates with HBV DNA suppression in chronic hepatitis B patients undergoing entecavir treatment. PLoS One 5: e13869, 2010.

56. Djouad F, Plence P, Bony C, Tropel P, Apparailly F, Sany J, Noël D and Jorgensen C: Immunosuppressive effect of mesenchymal stem cells favors tumor growth in allogeneic animals. Blood 102: 3837-3844, 2003.

57. Uzawa A, Mori M, Hayakawa S, Masuda S, Nomura F and Kuwabara S: Expression of chemokine receptors on peripheral blood lymphocytes in multiple sclerosis and neuromyelitis optica. BMC Neurol 10: 113, 2010

58. Wang T, Zhao H, Ren H, Guo J, Xu M, Yang R and Han ZC Type 1 and type $2 \mathrm{~T}$-cell profiles in idiopathic thrombocytopenic purpura. Haematologica 90: 914-923, 2005.

59. Ma XQ, Ma QY, Wang YY, Gu P and Wang MW: Protein secreted by bone marrow mesenchymal stem cells and its function. J Clin Rehab Tiss Engin Res 13: 2763-2766, 2009.

60. Liang C, Chen SL, Wang M, Zhai WJ, Zhou Z, Pang AM, Feng SZ and Han MZ: Synergistic immunomodulatory effects of interferon-gamma and bone marrow mesenchymal stem cells. Zhonghua Xue Ye Xue Za Zhi 34: 213-216, 2013 (In Chinese).

61. Dumoutier L, Van Roost E, Ameye G, Michaux L and Renauld JC: IL-TIF/IL-22: Genomic organization and mapping of the human and mouse genes. Genes Immun 1: 488-494, 2000.

62. Zhang Y, Cobleigh MA, Lian JQ, Huang CX, Booth CJ, Bai XF and Robek MD: A proinflammatory role for interleukin-22 in the immune response to hepatitis B virus. Gastroenterology 141: 1897-1906, 2011.

63. Park O, Wang H, Weng H, Feigenbaum L, Li H, Yin S, Ki SH, Yoo SH, Dooley S, Wang FS, et al: In vivo consequences of liver-specific interleukin-22 expression in mice: Implications for human liver disease progression. Hepatology 54: 252-261, 2011.

64. Hu WH and Ren J: Impact of hepatitis B virus infected serum on the hepatic differentiation of human bone marrow mesenchymal stem cells. Beijing Da Xue Xue Bao 40: 459-464, 2008 (In Chinese). 